\title{
IZOBRAŽEVALNE POTREBE ZAPOSLENIH IN PONUDBA NA TRGU
}

\section{Identifikacija potreb po usposabljanju in izobraževanju zaposlenih z vidika ponudnika seminarjev in delavnic}

Mag. Patrick

Vesel in dr.

Vesna Žabkar,

Fakulteta za

družbene vede

\section{POVZETEK}

Slovenski trg seminarjev in delavnic lahko označimo kot trg v stopnji zrelosti, na katerem je prisotna visoka stopnja konkurence; uspešno poslovanje na takšnem trgu je nedvomno velik poslovni izziv, pomen učinkovitega in uspešnega trženja pa igra pri tem pomembno vlogo. Avtorja skušata v članku izpostaviti pomen in razumevanje trženja storitev, kamor seveda štejemo dejavnost organiziranja seminarjev in delavnic. Posebnost se kaže predvsem y $t$. $i$. interaktivnem trženju, ki ga lahko razlagamo kot vez med ponudnikom seminarjev in delavnic ter kupcem odločevalcem oziroma udeležencem seminarja ali delavnice. Poleg tega moramo v trženjski funkciji obravnavane panoge izpostaviti tudi pomen razumevanja potreb ciljnega trga. Avtorja v raziskavi, ki je potekala med organizacijami v Slovenïji, združujeta teoretično in empirično. Izsledki raziskave, dobljeni s pomočjo multivariantnih statističnih metod, bralcu ponujajo vpogled v razumevanje potreb ciljnega trga; na osnovi dobljenih dimenzij pomembnosti (čutno zaznavanje, uporabnost, prikladnost, ugled, zasnova in globalnost) se trg loči v dva večja segmenta, na t. i. »zahtevne odločevalke« (55\%) in »iskalce znanj» $(45 \%)$.

Ključne besede: izobraževanje odraslih, konkurenčnost, trženje storitev

\section{UVOD}

Po mnenju Al-Khayyata in Elgamala (1997, str. 87) je v okolju nenehnih sprememb, visoke stopnje konkurence, demografskih sprememb delovne sile ter poslovnih ciklov usposabljanje in izobraževanje zaposlenih daleč najpomembnejša metoda, ki organizacijam zagotavlja fleksibilnost, prilagodljivost in stanovitnost. Še več, musposabljanje in izobraževanje zaposlenih ni več dojeto kot zapravljivost po uspešno zaključenem poslov- nem letu, ampak kot nujnost za dosego konkurenčnosti. Organizacij več ne skrbi to, da bi tisti zaposleni, ki so bili na usposabljanju in izobraževanju, odšli, ampak da bi tisti zaposleni, ki niso bili na usposabljanju in izobraževanju, ostali v organizacijik (Wild, A. Griggs, Downing, 2002, str. 373).

Če se torej organizacije vse bolj zavedajo pomena ustrezne usposobljenosti in izobraženosti svojih zaposlenih, je tovrstno zavedanje potrebno tudi s strani ponudnikov seminarjev 

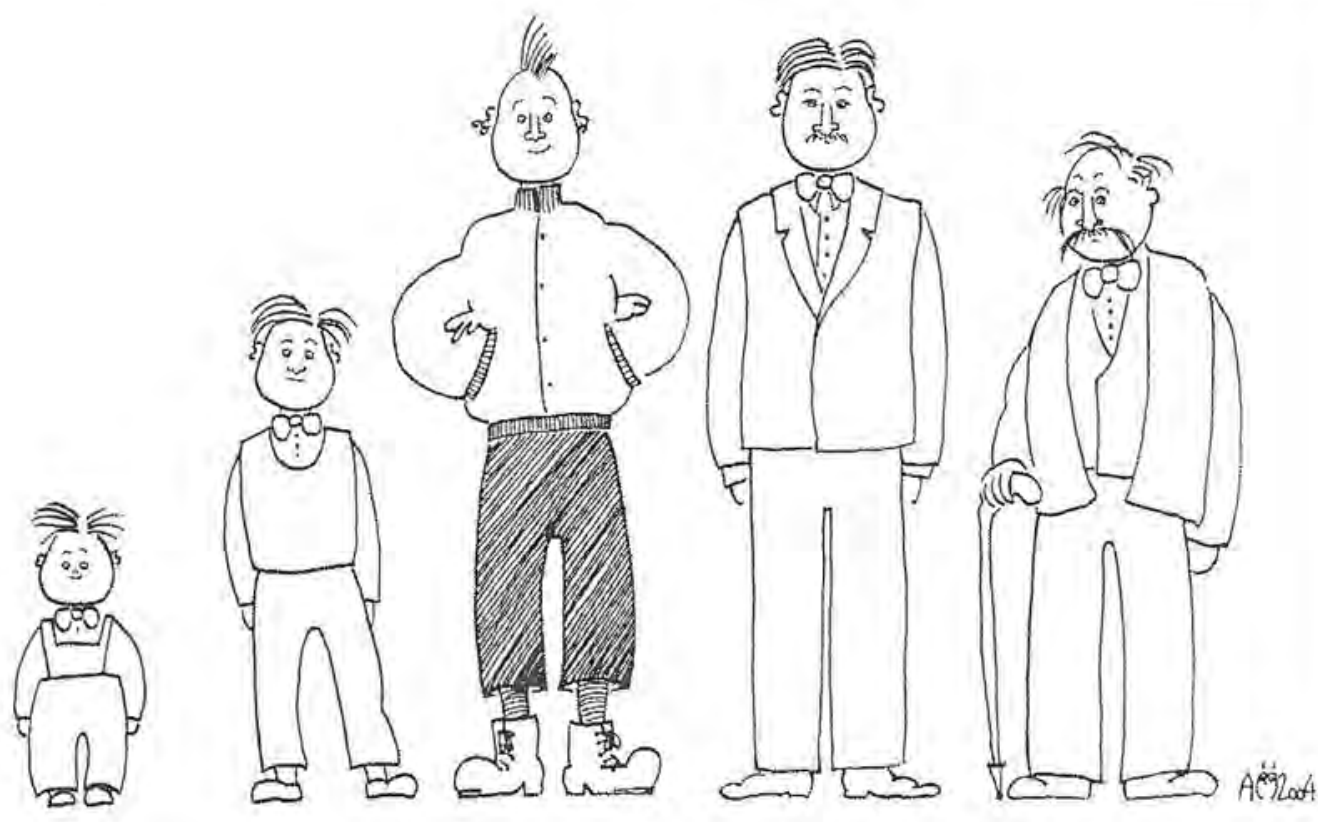

in delavnic, ki na trgu ponujajo eno izmed možnih oblik usposabljanja in izobraževanja zaposlenih. Lahko bi torej rekli, da mora ponudba slediti povpraševanju - in to ne zgolj $\mathrm{z}$ jedrom storitve, kot so času in prostoru primerne vsebine, pač pa tudi z dopolnilnimi storitvami, ki naj bodo odsev

Na izobraževalnem trgu imata enako pomembno vlogo tako vsebina kot tudi samo trženje. dejanskih tržnih potreb, saj je po mnenju Kotlerja (1998, str. 18) med drugim ključ uspeha poslovanja organizacij ravno $v$ tem, da so sposobne opredeliti potrebe in žèlje svojih ciljnih trgov. Po Marsellu (1998, str. 14) je trend pri pripravi seminarjev in delavnic predvsem v usmerjanju virov $v$ samo pripravo in zasnovo vsebin, bistveno manj pa $v$ proces trženja. $\mathrm{Ob}$ tem Marsell (prav tam) seveda ne zanemarja pomena kakovostnih učnih vsebin, saj brez tega ni mogoče pričakovati udeležbe na seminarjih in delavnicah, opozarja pa na to, da brez predanosti trženju ni moě pričakovati rasti podjetja, ki se s tovrstno dejavnostjo ukvarja. Učinkovito in uspešno trženje privablja nove udeležence seminarjev in delavnic, hkrati pa zadržuje obstoječe.

\section{SEMINARII IN DELAVNICE KOT STORITEV}

Ponudniki seminarjev in delavnic delujejo na trgu storitev. V literaturi obstaja mnogo definicij o storitvah, Grönroojeva (2001, str. 46) na primer pravi, da je wstoritev proces, sestavljen iz več bolj ali manj neotipljivih aktivnosti, ki ponavadi, a ne nujno vedno, nastajajo v interakciji med kupcem na eni strani in ponudnikom storitve s svojimi fizičnimi resursi ali dobrinami ter procesi na drugi strani, kar predstavlja dano rešitev za kupcar. Na kontinuumu, ki na eni strani prikazuje čisti izdelek, na drugi strani pa čisto storitev (Kotler, 1998, str, 465), lahko storitve ponudnikov seminarjev in delavnic uvrstimo na del, ki prikazuje storitev, spremljano z 
manj pomembnimi izdelki in/ali storitvami. To pomeni, da ne gre za čisto oziroma golo storitev, saj so poleg posredovanega znanja, ki je glavna storitev, udeleženci seminarjev in delavnic ponavadi deležni še nekaterih dodatnih otipljivih stvari, na primer hrane in pijače, učnega gradiva ipd, včasih pa tudi podpornih storitev, kot je prenočitev $v$ primeru večdnevnih seminarjev.

Storitve se od fizičnih izdelkov razlikujejo po številnih kriterijih (Grönroos, 2001, str. 48). Preneseno na storitve ponudnikov seminarjev in delavnic pa velja naslednje:

- Storitvam je pripisana narava procesa oziroma aktivnosti, ki se $v$ številnih primerih odvija celo $v$ neposredni povezavi $s$ kupcem. Ker kupec sodeluje v samem procesu nastanka in oblikovanja storitve, je tako mnogokrat tisti del, v katerem kupec sodeluje, že kar rešitev oziroma storitev sama. Udeleženci v programih usposabljanja in izobraževanja tako s svojim aktivnim sodelovanjem sooblikujejo proces nastanka storitve, npr. seminarja ali delavnice.

- Neločljivost pomeni, da sta izvajanje in poraba storitve izvedena istočasno, kar pa ne velja $v$ primeru seminarjev in delavnic, saj je ponavadi tisto, kar je "proizvedeno« (tj. posredovano znanje), (u)porabljeno (tj. pridobljeno znanje) kasneje na delovnem mestu.

- Minljivost pomeni, da storitve ni moč sproizvesti na zalogo. Za ponudnike seminarjev in delavnic to pomeni, da $v$ primeru, ko mesto ostane nezasedeno, tega ni več moč prodati.

- Neotipljivost pomeni, da se storitve fizično ni moč dotakniti, kar pa ne velja v celoti $\mathrm{v}$ primeru seminarjev in delavnic. Resda za osnovno storitev, tj. posredovano znanje ali veščine, velja narava nedotakljivosti, so pa ostali prisotni elementi $v$ obliki podpornih izdelkov, ki imajo naravo dotakljivosti (učno gradivo, postrežena hrana in pijača ipd.).
Slika 1: Prikaz tradicionalne vloge trżenja (levo) in vloge trženja v storitvenih podjetjih (desno)
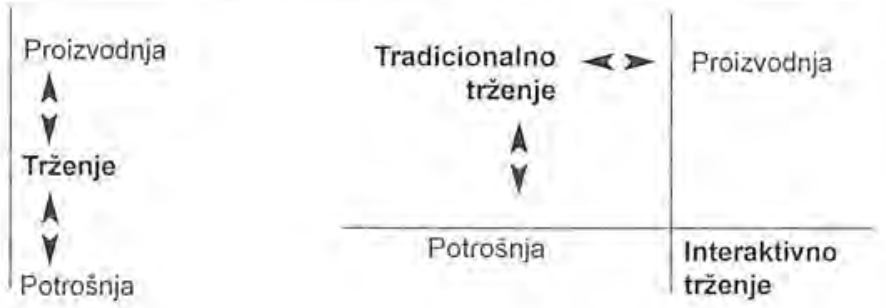

Vir: Grintroos, 2001, 518. 234 in 247.

- Nelastništvo pomeni, da v primeru storitev ni prenosa lastništva med prodajalcem in kupcem oziroma $v$ našem primeru uporabnikom; izjema so le podporni izdelki (npr: učno gradivo), ki na koncu ostanejo v lasti udeleženca.

- Spremenljivost pomeni, da se storitve spreminjajo, odvisno pač od tega, kdo jih izvaja, kje in kdaj. To lastnost lahko pripišemo tudi seminarjem in delavnicam, saj je kakovost določenega seminarja ali delavnice določena skozi subjektivna merila udeležencev, ki se med seboj lahko tudi razlikujejo.'

Zaradi predstavljenih značilnosti storitev Grönroos (2001, str. 232-263) meni, da je potrebno razlikovati trženjsko funkcijo $v$ storitvenih organizacijah in $v$ tradicionalnih proizvodnih organizacijah. Trženjska funkcija tako ni več zgolj vez med proizvodnjo in potrošnjo, ampak sestavni del tako faze proizvodnje (izvajanja) kot tudi faze potrošnje (porabe). Razliko med tradicionalno Trženje storitev je drugačno od trženja izdelkov. vlogo trženja in vlogo $v$ storitvenih organizacijah prikazuje slika 1 .

Trženjski splet sje niz trženjskilt instrumentov, ki jih podjetje uporablja, da sledi svojim trženjskim ciljem na ciljnem trgu« (Kotler,

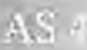


Koncept tako definiranega trženjskega spleta se pokaže kot neprimeren v primeru storitev, saj ponavadi implicitno zahteva ločen pristop funkcije trženja, kar paradoksalno povzroča, da so ravno tržniki najmanj v stiku s svojimi kupci. Ker so storitve proces, ki zahteva, da je stik med prodajalcem in kupcem (oziroma $\mathrm{v}$ primeru izvajanja seminarjev in delavnic med izvajalcem in uporabnikom) dlje časa trajajoč kot v primeru nakupa izdelka, saj se proizvodnja in potrošnja storitve ponavadi odvijata istočasno, kupec pa ima pri tem mnogokrat tudi aktivno vlogo pri razvoju storitve, je trženjsko vedenje tudi v domeni ostalih zaposlenih in ne samo tržnikov.

1998, str. 98). Grönroos (2001, str. 232-263) meni, da tradicionalno gledišče predstavlja trženje kot ločeno funkcijo $v$ organizaciji, ki skrbi za uspešno implementacijo trženjskega spleta. Ne glede na to, da so tradicionalnemu trženjskemu spletu (izdelek, cena, prodajne poti, tržno komuniciranje) za potrebe storitev dodani novi elementi (udeleženci pri izvajanju storitve, storitveni proces, fizično okolje

\section{Izobraževalne sto- ritve zahtevajo interaktivni trženjski pristop.} in fizični dokazi storitve (npr. Potočnik, 2000, str. 95), kritično podaja mnenje, da se takšna oblika kljub dodajanju novih elementov (Kotler 1986, v Grönroos, 2001, str. 241) - za primer megatrženja dodaja še odnose z javnostmi in politiko - mnogokrat kaže kot omejujoča, saj predstavljeni elementi niso ustrezni in univerzalni za vsako panogo, s časom pa postajajo tudi zastareli.

Popolna ločitev trženjske funkcije od ostalih je možna $v$ tradicionalnem proizvodnem okolju, kjer kupec ponavadi kupi in uporablja izdelek ločeno od proizvódnje. V primeru storitev tako gledišče ni pravilno, saj gre ponavadi za neločljivost izvajanja in porabe storitve.

$\mathrm{V}$ primeru storitev se tako pojavljata dve vlogi trženja, tradicionalna in interaktivna. $\mathrm{V}$ domeni prve, kjer so zaposleni tržniki, ki opravljajo samo to funkcijo, je skrb za tra- dicionalen trženjski splet, $v$ domeni druge, izvajane $\mathrm{z}$ zaposlenimi, ki opravljajo tudi druge, »netrženjske « delovne naloge, pa skrb za odnos s kupcem $v \gg$ trenutkih resnice . $^{2}$

Pri tem je seveda pomembno, da sta tradicionalna in interaktivna oblika trženja usklajeni, saj v primeru, ko tradicionalno trženje pri kupcih ustvarja previsoka pričakovanja glede na sposobnosti interaktivnega trženja, med uporabniki to lahko privede do nezadovoljstva s storitvijo. Zaznana kakovost je namreč nižja od pričakovane (Grönroos, 2001, str. 99 in 246-249). Ravno zato je identifikacija potreb po usposabljanju in izobraževanju izjemnega pomena. Če potrebe in želje ciljnih trgov povežemo s pričakovanji ciljnih trgov in so torej pričakovanja ciljnih trgov odraz njihovih potreb in želja, potem je po mnenju Zeithamla, Parasuramana in Berryja (1990, str. 51) poznavanje pričakovanj ključnega pomena za oblikovanje kakovostnih storitev. Mnogokrat namreč nastane vrzel med tem, kaj kupec (oziroma v našem primeru tudi porabnik) dejansko pričakuje in káj menedžment meni, da je pričakovano. V tem primeru podjetje ponuja storitve, ki se ne ujemajo s kupčevimi pričakovanji; kupcu pomembni elementi ponudbe so izvzeti, raven kakovosti vsebovanih elementov pa je glede na stopnjo pomembnosti neustrezna.

\section{TRŽENISKA RAZISKAVA SLOVENSKEGA TRGA SEMINARJEV IN DELAVNIC}

Izsledki trženjske raziskave, ki je potekala na področju Republike Slovenije v času od 9. 3. 2004 do vključno 9. 4. 2004, ponudnikom seminarjev in delavnic omogočajo izognitev prav temu, tj. nastanku vrzeli med smenedžerskim védenjem in poznavanjem potreb trga«, tistih, ki ponujajo seminarje in delavnice, ter med smenedžerskim védenjem in poznavanjem potreb $\ll$ tistih, ki se $\mathrm{v}$ organizacijah ukvarjajo s tovrstnim delom. 
Vzorčna enota je bila namreč tista oseba v organizaciji $\mathrm{z}$ več kot pet zaposlenimi $\vee \mathrm{Re}$ publiki Sloveniji, ki se v okviru svojih delovnih nalog ukvarja s pošiljanjem zaposlenih na seminarje in delavnice ter odločanjem $\mathrm{v}$ zvezi $\mathrm{s}$ tem in je že bila prisotna na kakšnem seminarju ali delavnici. Pri tem je pomembno poudariti, da so anketirani nastopali tako $v$ vlogi odločevalca glede usposabljanja in izobraževanja zaposlenih kot tudi v vlogi udeleženca katerega od ponujenih seminarjev ali delavnic na trgu. Vzorčni okvir je predstavljala podatkovna baza IPIS - Poslovni register Slovenije, junij 2003, raziskovalni inštrument je bil pisni vprašalnik, oblika komuniciranja pa metoda anketiranja po pošti. V raziskavo so bile vključene organizacije s pet in več zaposlenimi, ${ }^{4}$ glede na pričakovane stopnje odziva pa je bil izbran neproporcionalni stratificirani vzorec (Churchill, 1996, str. 517), v katerega je bilo zajetih 600 mikro organizacij z več kot petimi zaposlenimi, 600 majhnih, 500 srednjih in 300 velikih organizacij.s Stopnja odziva je znašala 15,1 odstotek, podatki pa so bili obdelani s statističnima programskima paketoma SPSS 11.0 for Windows in The SAS System for Windows V8. S pomočjo metode uteževanja je vzorec reprezentativen glede na velikost organizacij.

\section{OPERACIONALIZACIJA VPRAŠALNIKA - ANALIZA POMEMBNOSTI IN IZVEDBE}

Avtorja modela Martilla in James (1977, str. 77-79) $v$ analizi pomembnosti in izvedbe vidita predvsem njeno praktično naravnanost. Menita, da analiza ponuja številne prednosti za ocenjevanje trženjske ponudbe, med katerimi izstopa predvsem enostavnost v razumevanju tehnike in možnost uvida tako na tista področja trženjskega spleta, ki zahtevajo dodatno usmerjenost, kot tudi na tista, na katerih je potrošenih preveč virov.
Možnost grafične predstavitve rezultatov povečuje interpretacijsko raven same metodologije in tako še dodatno prispeva $\mathrm{k}$ uporabnosti pri sprejemanju strateških trženjskih odločitev.

Ennew, Reed in Binks (1993, str. 59) menijo, da gre za relativno preprost koncept, $\mathrm{ki}$ vključuje primerjavo kupčevih pričakovanj o storitvi na eni strani ter zaznave same učinkovitosti storitve na drugi strani. Metodólogija je primerna tako za uporabo preprostejših orodij, na primer primerjavo povprečij ujemanj oziroma neujemanj posameznih ocenjevanih elementov, kot tudi za uporabo zahtevnejših statističnih metod, na primer faktorske analize. Razširjenost uporabe analize sega na številna področja storitev (Ford, Joseph, Joseph, 1999, str. 173), Joseph in Joseph (1997, str. 17) pa celo menita, da gre za najprimernejšo tehniko merjenja kakovosti v izobraževalnih storitvah, kamor se po številnih kriterijih uvršča tudi usposabljanje in izobraževanje zaposlenih.

Analiza pomembnosti in izvedbe temelji na paradigmi nepotrditve, saj identificira prednosti in slabosti na osnovi ujemanja (oziroma neujemanja) dveh kriterijev: pomembnosti posameznih elementov, tj. vprašanje o tem, kako pomemben se zdi vprašanemu nek element ponudbe ter ocene o izvedbi posameznega elementa, tj. vprašanje o tem, kako

Slika 2: Matrika pomembnosti in izvedbe

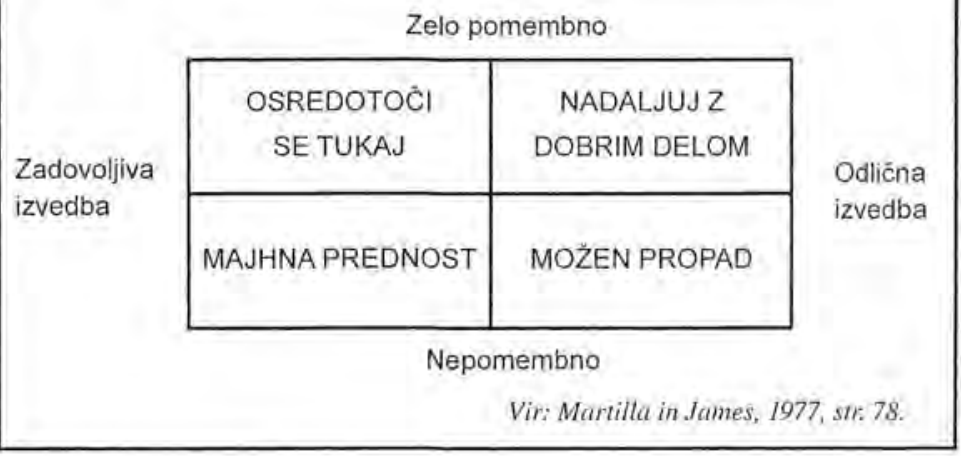


dobro je nek ponudnik izpolnil pričakovanja in zahteve $v$ zvezi s posameznim elementom. $\mathrm{Na}$ osnovi ocen Likertove lestvice se rezultati uvrstijo v štiri možna polja (glej sliko 2).

\section{DEMOGRAFSKI PODATKI ANKETIRANCEV IN OSNOVNI PODATKI O ORGANIZACIJAH}

V raziskavi je sodelovalo 70 odstotkov žensk in 30 odstotkov moških (slika 3). Povprečna starost anketiranega je znašala 41 let. Največ anketiranih je bilo starih med 41 in 50 let ( 35 odstotkov), najmanj pa je bilo takšnih, ki so bili stari do 30 let (16 odstotkov) (slika 4).

Večina anketiranih je imela vodstveni položaj v organizaciji (slika 5); 11 odstotkov je bilo takšnih, ki so bili lastniki organizacije, 34 odstotkov pa takšnih, ki so bili glavni oziroma $v$ višjem menedžmentu organizacije. Skoraj 90 odstotkov vprašanih je imelo dokončano več kot srednjo šolo (slika 6).

Glede na statusno ureditev je bilo največ organizacij urejenih $v$ obliki družb $z$ omejeno odgovornostjo (43 odstotkov), najmanj pa v obliki ureditve samostojnega podjetnika (2 odstotka) (slika 7).

Pred postopkom uteževanja je po velikostni strukturi organizacij največji delež pripadal srednje velikim (38 odstotkov) ter majhnim organizacijam (30 odstotkov). Delež velikih in mikro organizacij je bil manjši, in sicer 20 odstotkov ter 12 odstotkov (slika 8). Z metodo uteževanja smo vpliv velikostnih deležev prilagodili dejanskim populacijskim vrednostim (2,4 odstotka velikih organizacij, 11,4 odstotkov srednje velikih organizacij, 37 odstotkov srednjih organizacij in 49,2 odstotkov mikro organizacij z vsaj petimi zaposlenimi) in tako pripravili reprezentativen vzorec glede na velikost organizacij.

Glavna dejavnost organizacij po Standardni klasifikaciji dejavnosti (SKD) je organizacije ločevala po dejavnosti, s katero ustvarijo pre-
Slika 3: Spolna struktura anketirancev

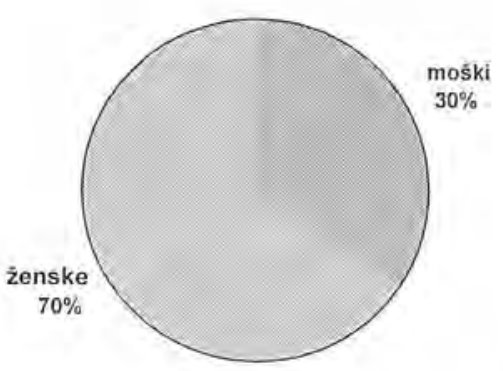

Vir: Lasma maziskava, 2004, $N=302$.

Slika 4: Starostna struktura anketirancev

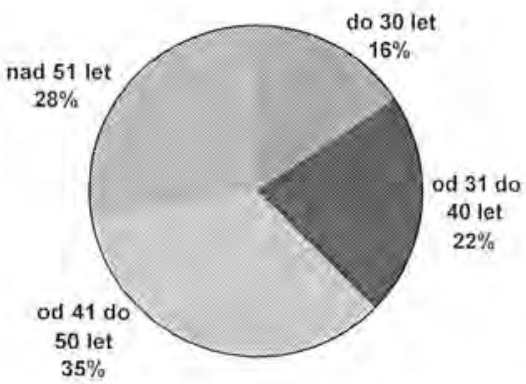

Vir: Lastma riziskara, 2004, $N=298$.

Slika 5: Status anketiranca v organizaciji

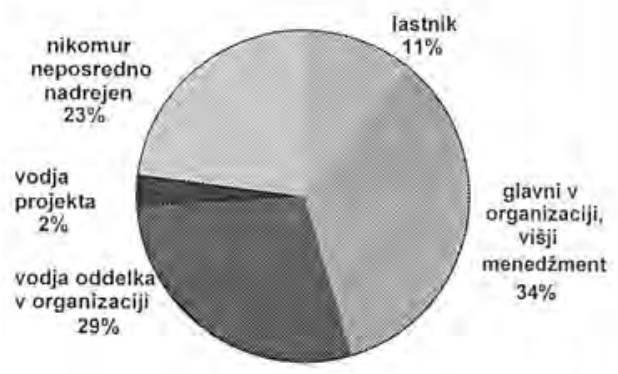

Vir: Lastna raziskava, 2004. $N=302$. 
Slika 6: Izobrazbena struktura anketirancev

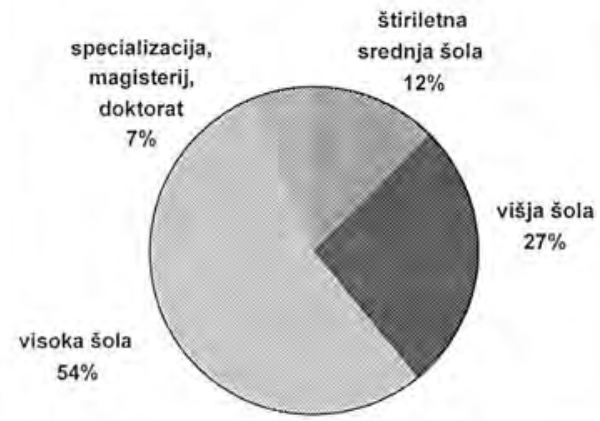

Vir: Lastna raziskava, 2004, $N=302$.

Slika 7: Statusna oblika organizacij

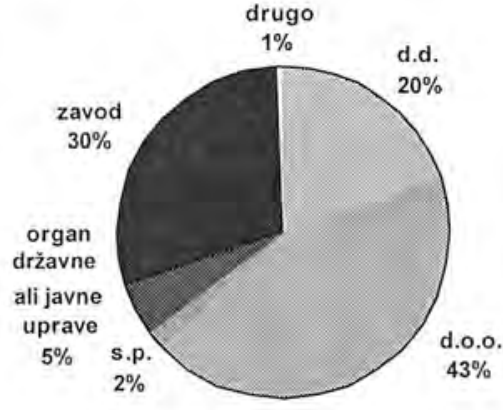

Vir: Lastna raziskava, 2004, $N=302$.

Slika 8: Velikostna struktura organizacij

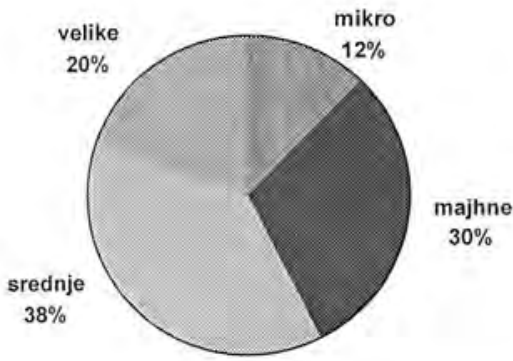

Vir: Lastha raziskava, 2004, $N=302$. težni del prihodkov. Največji delež organizacij se je ukvarjal s predelovalnimi dejavnostmi (21 odstotkov), izobraževanjem (20 odstotkov) in trgovino, popravili motornih vozil ter izdelki široke porabe (16 odstotkov). Ostale dejavnosti so imele deleže manjše od 10 odstotkov (glej tabelo 1).

\section{OPERACIONALIZACIJA SPREMENLIIVK}

$\mathrm{S}$ prvo skupino spremenljivk $\mathrm{v}$ analizi pomembnosti in izvedbe, ki merijo pomembnost posameznih elementov ponudbe seminarjev in delavnic, smo skušali s pomočjo faktorske analize ${ }^{6}$ ugotoviti tiste dimenzije, $\mathrm{ki}$ tvorijo konstrukt pomembnosti posameznih elementov.

Tabela 1: Deleži organizacij v vzorcu glede na Standardno klasifikacijo dejavnosti

\begin{tabular}{|l|c|}
\hline $\begin{array}{l}\text { Standardna klasifikacija dejavnosti } \\
\text { (SKD) }\end{array}$ & Delež v \% \\
\hline Predelovalne dejavnosti & 21 \\
\hline Izobraževanje & 20 \\
\hline $\begin{array}{l}\text { Trgovina, popravila motornih vozil in } \\
\text { izdelkov široke porabe }\end{array}$ & 16 \\
\hline Gradbeništvo & 6 \\
\hline $\begin{array}{l}\text { Poslovanje z nepremičninami, najem in } \\
\text { poslovne storitve }\end{array}$ & 6 \\
\hline $\begin{array}{l}\text { Dejavnost javne uprave, skupne in } \\
\text { osebne storitvene dejavnosti }\end{array}$ & 6 \\
\hline Zdravstvo in socialno varstvo & 6 \\
\hline Promet, skladiščnje in zveze & 4 \\
\hline $\begin{array}{l}\text { Druge javne, skupne in osebne } \\
\text { storitvene dejavnosti }\end{array}$ & 4 \\
\hline $\begin{array}{l}\text { Gostinstvo } \\
\text { vodo }\end{array}$ & 2 \\
\hline Finančno posredništvo & $\mathbf{2}$ \\
\hline Kmetijstvo, lov, gozdarstvo & $\mathbf{2}$ \\
\hline Drugo & (skrbačno energijo, plinom in \\
\hline
\end{tabular}

Vir: Lastna raziskava, 2004, $N=302$. 
Tabela 2: Dimenzije pomembnosti elementov ponudbe seminarjev in delavnic

\begin{tabular}{|c|c|}
\hline $\begin{array}{l}\text { Dimenzija } \\
\text { pomembnosti }\end{array}$ & Vsebovane spremenljivke \\
\hline $\begin{array}{l}\text { Cutno } \\
\text { zaznavanje }\end{array}$ & $\begin{array}{l}\text { Vizualno privlačno oblikovana } \\
\text { gradiva } \\
\text { Urejenost predavatelja } \\
\text { Prijaznost in korektnost } \\
\text { administrativnega osebja } \\
\text { Ponudba že v ceno vštetega } \\
\text { kosila } \\
\text { Urejenost spremljajočega osebja } \\
\text { Prijaznost spremljajočega osebja }\end{array}$ \\
\hline Uporabnost & $\begin{array}{l}\text { Aktualnost vsebine } \\
\text { Kakovostna učna gradiva } \\
\text { Praktični primeri iz poslovnih in } \\
\text { drugih praks } \\
\text { Sproščeno vzdusje na seminarju } \\
\text { ali delavnici } \\
\text { Kombinacija praktičnega in } \\
\text { teoretičnega v obliki študije } \\
\text { primerov } \\
\text { Možnost prenosa pridobljenih } \\
\text { znanj in veščin na delovno mesto }\end{array}$ \\
\hline Prikladnost & $\begin{array}{l}\text { Dan v tednu, ko se seminar ali } \\
\text { delavnica odvijata } \\
\text { Potek seminarja ali delavnice } \\
\text { izven delovnega časa } \\
\text { Oddaljenost kraja, kjer se } \\
\text { seminar ali delavnica odvijata } \\
\text { Potek seminarja ali delavnice } \\
\text { znotraj delovnega časa } \\
\text { Kraj v Sloveniji, kjer se seminar } \\
\text { ali delavnica odvijata }\end{array}$ \\
\hline Ugled & $\begin{array}{l}\text { Ugled podjetja, ki organizira } \\
\text { seminar ali delavnico } \\
\text { Ugled predavatelja }\end{array}$ \\
\hline Zasnova & $\begin{array}{l}\text { Jasnost in doslednost koncepta } \\
\text { seminarja ali delavnice } \\
\text { Možnost odprtih diskusij na } \\
\text { seminarju ali delavnici }\end{array}$ \\
\hline Globalnost & $\begin{array}{l}\text { Gostovanje tujih predavateljev } \\
\text { Izvedba seminarja ali delavnice } \\
\text { v tujini }\end{array}$ \\
\hline
\end{tabular}

Vir: Lastna raziskava, 2004.
Pri oblikovanju seznama elementov ponudbe smo sledili Barcali, Martínu in Gutiérrezu (2000, str. 243-260), ki so izvajali podobno raziskavo med španskimi trgovci na drobno. Seznam smo na podlagi literature še dodatno dopolnili in ga tako skušali približati trgu seminarjev in delavnic $\mathrm{v}$ slovenskem prostoru. Pri tem smo skušali z različnim vrstnim redom trditev z dvema različnima tipoma vpraŠalnikov zmanjšati vpliv zaporedja trditev na odgovore anketirancev.

Anketiranci so na podlagi kriterijev, ki jih imajo kot odločevalci na področju usposabljanja in izobraževanja zaposlenih, izražali stopnjo pomembnosti posameznih elementov s pomočjo Likertove lestvice, kjer je 1 pomenilo, da element sploh ni pomemben, 5 pa, da je zelo pomemben. Prav tako so s pomočjo Likertove lestvice na podlagi izkušenj kot udeleženci izobraževanja oz. usposabljanja ocenili izvedbeno raven posameznih elementov, pri čemer je 1 pomenilo, da potrebe in pričakovanja $\vee$ zvezi s posameznim elementom sploh niso bili izpolnjeni, 5 pa, da so bili izpolnjeni $v$ celoti.

Iz nabora 36 trditev smo zaradi nizkih korelacijskih vrednosti spremenljivk, vsebinske neskladnosti $v$ sestavi faktorjev ali zaradi težav z nizkimi oziroma na več faktorjev porazdeljenimi faktorskimi utežmi, izločili 13 spremenljivk. Na osnovi 23 spremenljivk smo tako dobili 6 dimenzij, ki tvorijo konstrukt pomembnosti elementov ponudbe seminarjev in delavnic (glej tabelo 2).

$\mathrm{S}$ šestimi dejavniki smo tako uspeli pojasniti 48 odstotkov variabilnosti opazovanih spremenljivk, ostalo pa je vpliv specifičnih dejavnikov. Ustreznost podatkov za metodo faktorske analize potrjuje vrednost Keiser-MeyerOlkinove mere ustreznosti vzorca, ki znaša 0,732 , ter zavrnitev ničelne hipoteze Bartlettovega testa sferičnosti, ki testira domnevo o enakosti korelacijske matrike $\mathrm{z}$ enotsko. Odločitev o številu faktorjev potrjuje 
tako diagram lastnih vrednosti kot tudi kriterij lastnih vrednosti, večjih od 1 . Zanesljivost konstrukta pomembnosti je merjena $\mathrm{z}$ vrednostjo Cronbachove, ki znaša 0,7982. Delni koeficienti zanesljivosti posameznih dimenzij pomembnosti znašajo: čutno zaznavanje 0,8018 , uporabnost 0,7876 , prikladnost 0,7325 , ugled 0,5910 , zasnova 0,6947 ter globalnost 0,6148 .

\section{GLAVNE UGOTOVITVE RAZISKAVE}

Na osnovi šestih dimenzij pomembnosti, ki smo jih ugotovili s faktorsko analizo, smo izvedli analizo pomembnosti in izvedbe. $\mathrm{Z}$ analizo smo skušali ugotoviti potencialne priložnosti in nevarnosti na slovenskem trgu seminarjev in delavnic. Analizo smo izvedli na osnovi dveh skupin vprašanj; prva je merila pomembnost predstavljenih elementov, druga pa uspešnost izvedbe. $\mathrm{S}$ pomočjo metod razvrščanja $v$ skupine ${ }^{7}$ pa smo skušali identificirati morebiten obstoj različnih segmentov odločevalcev glede udeležbe na seminarjih in delavnicah. Pri tem so kot kriterij razvrščanja služile ugotovljene dimenzije pomembnosti (čutno zaznavanje, uporabnost, prikladnost, ugled, zasnova in globalnost).

Na osnovi drevesa združevanja in kriterijev o merljivosti, velikosti, dostopnosti, diferenciranosti in operativnosti segmentov (Kotler, 1998, str. 281) se odločamo za dve skupini. Pri tem smo v vsaki skupini za vsako dimenzijo posebej na osnovi spremenljivk, iz katere je posamezna dimenzija sestavljena (glej tabelo 3), izračunali centroide vrednosti pomembnosti in izvedbe. Za postavitev osi $v$ koordinatnem sistemu smo na podlagi obeh skupin in vseh 23 spremenljivk izračunali centroida vrednosti pomembnosti in izvedbe ter na osnovi danih vrednosti določili izhodišča osi. Martilla in James (1977, str. 79) menita, da gre pri postavitvi osi za »stvar presoje«, opozarjata pa na to, da je pri tem potrebno biti pazljiv in poudariti relativne razlike med prikazanimi elementi. Ocenjujemo, da omenjeni pristop poudarja relativne razlike, hkrati pa je $\mathrm{z}$ vidika interpretacije enostaven za razumevanje.

Tabela 3 prikazuje vrednosti centroidov po skupinah tako po pomembnosti posameznih dimenzij kot tudi po kriteriju ocene izvedbe. Pri tem v primeru dimenzij pomembnosti med skupinama obstajajo statistično značilne raz-
Odlocitev za seminar je odvisna tudi od čutnega zaznavanja. like, kar potrjujejo prikazani intervali zaupanja na sliki 9.

\section{RAZLIKE MED SEGMENTOMA ODLOČEVALCEV GLEDE UDELEŽBE NA SEMINARIIH IN DELAVNICAH}

$\mathrm{V}$ prvem segmentu je glede na vzorec povečan delež žensk (več kot dve tretjini), pri tem pa gre za relativno zahtevne odločevalce glede udeležbe na seminarjih in delavnicah, saj jim poleg dimenzij zasnove in uporabnosti predstavljajo pomemben element ponudbe tudi dimenzije prikladnosti, ugleda in čut-

Tabela 3: Prikaz centroidov vrednosti dimenzij pomembnosti po skupinah

\begin{tabular}{|l|c|c|c|c|}
\hline & \multicolumn{2}{|c|}{ 1. skupina } & \multicolumn{2}{c|}{ 2, skupina } \\
\hline Dimenzija & Pomembnost & Izvedba & Pomembnost & Izvedba \\
\hline Zasnova & 4,61 & 3,88 & 4,45 & 4,03 \\
\hline Uporabnost & 4,56 & 3,79 & 4,37 & 3,86 \\
\hline Ugled & 4,00 & 3,97 & 3,56 & 3,88 \\
\hline $\begin{array}{l}\text { Cutno } \\
\text { zaznavanje }\end{array}$ & 4,00 & 3,81 & 3,29 & 3,79 \\
\hline Prikladnost & 4,03 & 3,77 & 2,84 & 3,81 \\
\hline Globalnost & 3,03 & 2,40 & 2,15 & 2,57 \\
\hline Skupaj & Pomembnost & 3,87 & Izvedba & 3,68 \\
\hline
\end{tabular}

Vir: Lastna raziskava, 2004 
Slika 9: Prikaz 95 odstotkov intervalov zaupanja posameznih dimenzij pomembnosti med segmentoma
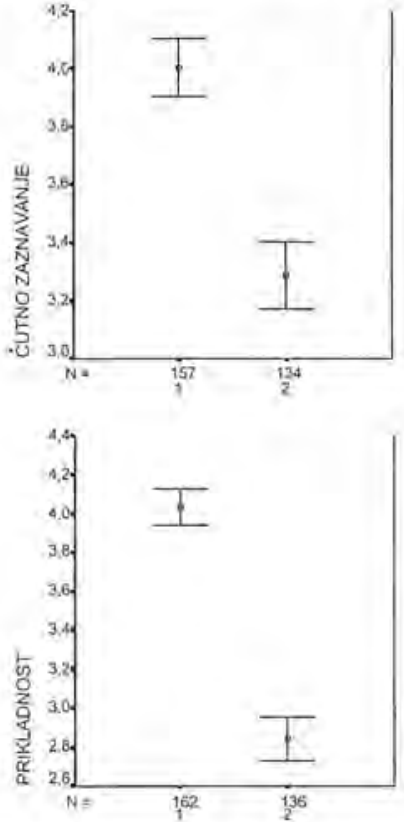
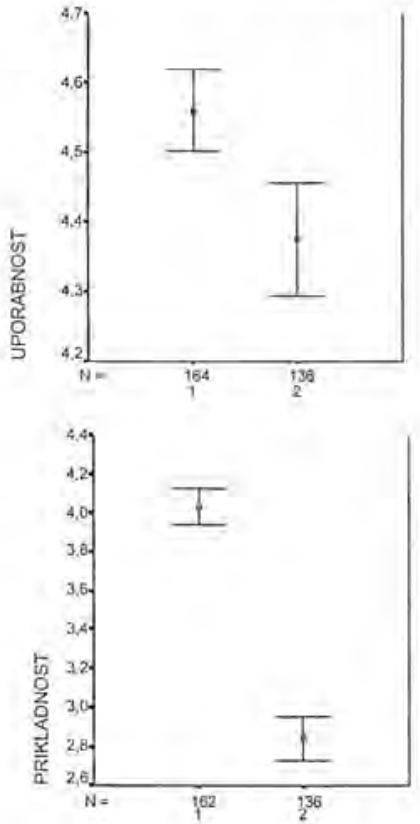

Vir: Lasina raziskava, 2004.
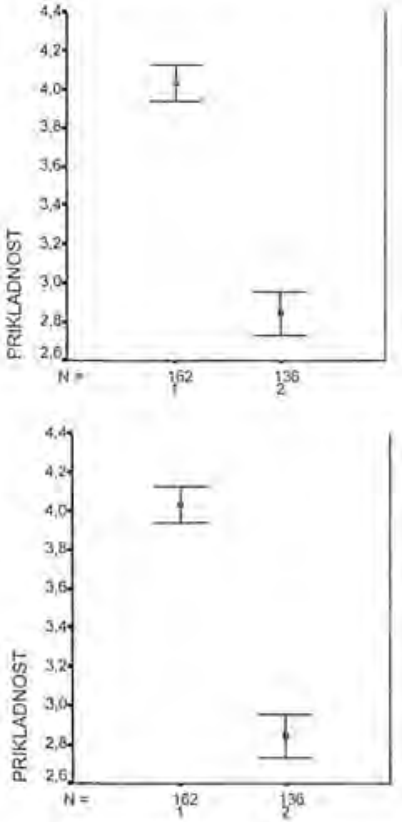

nega zaznavanja (glej sliko 10).

$\mathrm{V}$ drugem segmentu je glede na vzorec povečan delež moških (približno 45 odstotkov), odločevalcem v tej skupini pa se izmed dimenzij pomembnosti zdita pri ponudbi se-

55 odstotkov udeležencev izobraževanj izbira program tudi glede na dopolnilne storitve. minarjev in delavnic pomembni predvsem dimenziji zasnove in uporabnosti (glej sliko 11).

Oba segmenta sta si dokaj enotna $v$ tem, da je gostovanje tujih predavateljev ali izvedba seminarja ali delavnice $v$ tujini manj pomemben element ponudbe (dimenzija globalnosti). Segmentoma smo glede na ugotovljene lastnosti dodelili tudi imena: prvi in nekoliko večji segment smo poimenovali »zahtevne odločevalke« (55 odstotkov), drugega pa »iskalci znanj« (45 odstotkov). pomembnost posameznih dimenzij povzemamo Lovelockovo, Vandermerwejovo in Lewisovo (1999, str. 297) terminologijo, ki poenostavljeno deli zasnovo storitve na t. i. jedro storitve in na dopolnilne storitve. Po njihovi terminologiji lahko torej rečemo, da so manj zahtevni siskalci znanj« (45 odstotkov) osredotočeni predvsem na jedro storitve (dimenziji zasnove ter uporabnosti), »zahtevne odločevalke« (55 odstotokv) pa tako na jero kot tudi na dopolnilne storitve (dimenzije prikladnosti, ugleda in čutnega zaznavanja).

\section{DOPUSTNO OBMOČJE}

Berry in Parasuraman (1991, str. 58) definirata dopustno območje $»$ kot mejo kakovosti izvedbe storitve, ki jo kupec smatra kot zadovoljujočo. Izvedba pod ravnijo dopustnega območja povzroči kupčevo razočaranje in zmanjša kupčevo zvestobo, izvedba nad rav- 
nijo dopustnega območja pa kupca prijetno preseneti in okrepi njegovo zvestobo.«

Če primerjamo rezultate analize pomembnosti in izvedbe $\mathrm{z}$ rezultati Josepha in Josepha (1997, str. 20) ter Forda, Josepha in Josepha (1999, str. 179 in 182), ko skušajo meriti zaznavanje kakovosti izobraževalnih institucij pri študentih, lahko ugotovimo, da tudi rezultati raziskave slovenskega trga seminarjev in delavnic odsevajo podobno sliko, tj. pojav zaznavanja kakovosti $v$ dopustnem območju. Namreč kljub temu, da so vse dimenzije pomembnosti, razen dimenzije globalnosti, na desni strani matrike pomembnosti in izvedbe (glej sliki 4 in 5), to še ne pomeni, da je kakovost izvedbe takšna, kot bi lahko bila, tj. da bi bile vse dimenzije pomaknjene skrajno proti desni strani, kar bi potrjevalo izjemno zadovoljstvo udeležencev seminarjev in delavnic na slovenskem trgu. Tu pa se kaže priložnost in prostor za tiste ponudnike seminarjev in delavnic, ki stremijo $\mathrm{k}$ diferenciaciji njihovih storitev $\mathrm{v}$ obliki navduševanja udeležencev in kupcev seminarjev in delavnic.

\section{SKLEPNA MISEL}

Upoštevaje dejstvo, da je $v$ dejavnosti organiziranja seminarjev in delavnic na slovenskem trgu prisotna visoka stopnja konkurence, po značilnostih pa gre za trg v stopnji zrelosti, je izziv, ki ga predstavlja poslovanje na takšnem trgu, ogromen. Če pri tem vemo, da na slovenskem trgu obstajata dva večja segmenta odločevalcev glede udeležbe na seminarjih in delavnicah, prvega in nekoliko večjega predstavljajo t. i. "Zahtevne odločevalke ( 55 odstotkov), drugega pa t. i. »iskalci znanjk (45 odstotkov). Glede na teorijo dopustnega območja še vedno obstaja prostor za izboljšavo kakovosti ponudbe, zato obstaja dobro izhodišče za optimiziranje procesa trženja v podjetjih, ki se s tovrstno dejavnostjo ukvarjajo.

Po mnenju Shensona (1990, str. 11) naj bi
Slika 10: Prikaz centroidov vrednosti 1. segmenta v matriki pomembnosti in izvedbe

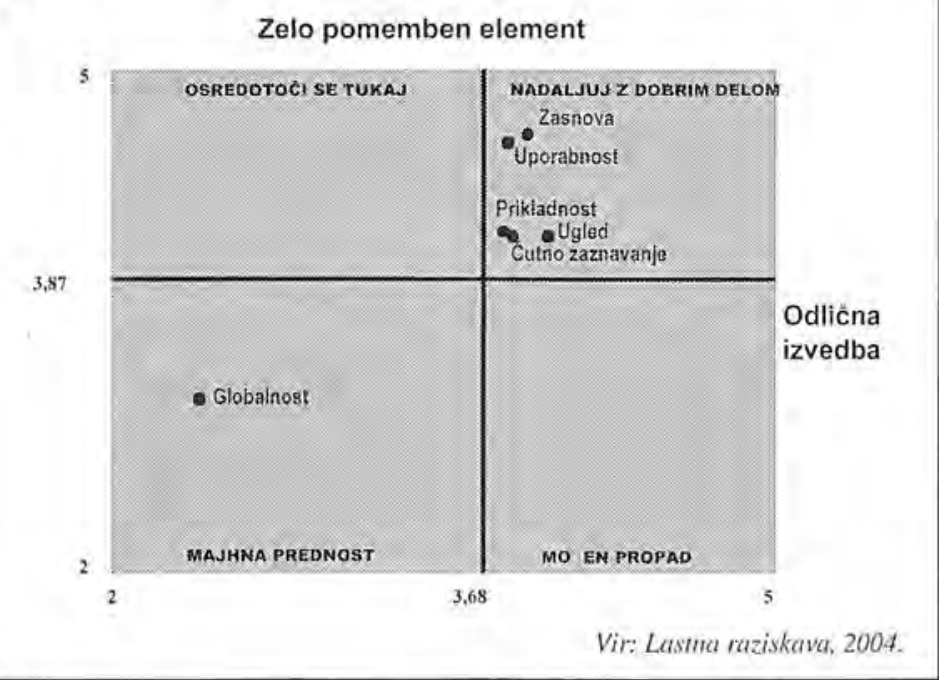

dober seminar ali delavnica v 60 odstotkih posredovala znanje, 40 odstotkov pa naj bi bilo namenjenih gostoljubju udeležencev. Lovelock, Vandermerwejeva in Lewiseva menijo, da je dobro zasnovana storitev skupek znanosti in umetnosti (1999, str. 294). Kolikšen je pri tem delež znanosti in kolikšen umetnosti, pravzaprav niti ni pomembno pomembno pa je, da skupek obojega pred-

Slika 11: Prikaz centroidov vrednosti 2 . segmenta v matriki pomembnosti in izvedbe

\section{Zelo pomemben element}

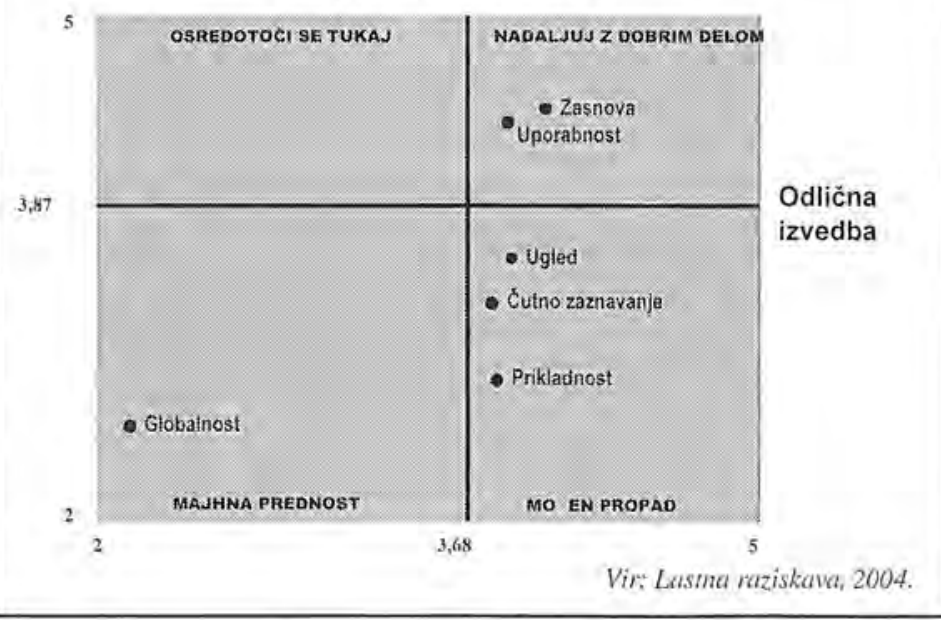


stavlja dobro in kakovostno zasnovano storitev.

\section{LITERATURA}

Al-Khayyat, M. R., Elgamal, A. M. (1997). A nacro model of tratuing and development: validation. Journal of European Industrial Training, 21, str. 87-101.

Barcala Ferníndez, M., Martín Díaz, M. A. Gutiérrez Trespalacios, A. J (2000). Training in retililing: a guide for improving the supply of courses. International Journal of Retail \& Distribution Management, 28, str. 243-260.

Barry, H., Milner, B. (2002). SMEs and electronic commerce: a departure from traditional prioritisation of training? Journal of European Industrial Training, 26, str. 316-326.

Berry, L. L., Purasuraman, A. (1991). Marketing services. Competing through quality. New York: The Free Press.

Chuchill, A. G. Jr. (1996). Basic Marketing Research. 3rd edition. New York: The Dryden Press.

Commission Recommendation of 6 May 2003 concerning the definition of micro, small and medium-sized enterprises (2003/361EC). Official Journal of European Union.

Ennew, T. C., Reed, V. G., Binks, R. M. (1993). Importance-Performance Analysis and the Measurement of Service Quality. European Journal of Marketing, 27, str. 59-70.

Ford, B. J., Joseph, M.. Joseph, B. (1999). Importanceperformance analysis as a strategic tool for service marketers: the cise of service quality perceptions of business students in New Zealand and the USA. The Journal of Services Marketing, 13, str. 171-186.

Grönroos, C. (2001), Service Management and Marketing, New York: John Wiley \& Sons, Lid.

Joseph, M., Joseph, B. (1997). Service quality in education; it student perspective. Quality Assurance in Education, 5, sir. $15-21$.

Kotler, P. (1998). Trženjsko upravljanje: unalizi, načrtovanje, izvajanje in nadzor. 2. popravljena izdajat. Ljubljana: Slovenska knjjiga.

Lovelock, C., Vandermerwe, S., Lewis B. (1999), Services Marketing. A European Perspective. London: Prentice Hall Europe.

Marsello, G. (1998). Developing a one-year marketing plan. Manhattan: Learning Resources Network, LERN.

Martilla, A. J., James, C, J. (1977). ImportancePerformance Analysis. Journal of Marketing, 41, str. 77-79.

Matlay, H. (2002). Training and HRD strategies in family and non-family owned small businesses: a comparative approach. Education + Training, 44, str. 357-369.

Mramor, D., Valentinčič, A. (2003). Forecisting the liquidity of very small private companies. Journal of Business Venturing, 18, str. 745-771.

Potočnik, V. (2000). Trženje storitev. Ljubljana: Gospodarski vesmik.

Sharma, S. (1996). Applied Multivariate Techniques. New York: John Wiley \& Sons.

Shenson, L. H. (1990). Successful Seminars \& Workshops. New York: John Wiley \& Sons, Inc.
Wild, H. R., Griggs, A. K., Downing T. (2002). A framework for e-learning as it tool for knowledge management. Industrial Management \& Dala Systems, 102. str. $371-380$.

Zeithaml, A. Y., Parasusuman, A. Berry, L. L. (1990). Delivering Quality Service. New York: The Free Press.

I Ravno zato velja izpostaviti pomen evalvacije, saj madi vpogled v sam proces in tako tudi mošnosti a korekcije p primerih, ko je to potrebule.

${ }_{7}^{2}$ Grönmos v lem primenu ločuje med $t, i$, trăniki ws polnin delovnim časom in m:niki as polovičnth delovnin casoma (ang. full-time marketers in part-time marketers), proces v nastajanju storitve, ki nastane zarudi neločljivosti proizvodnje in potrošnje med kupcem in prodajalcem pa po Normannu poimenuje trenutki resnice (ang, sinomens of truthe) (Grömroos, 2001, str: 72).

3 Voglasu ponudnik seminarjev na primer oglašuje visoko razvite komunikucijske sposobnosti predanulelja. na seminarju pa so udeleženci priča povsem povprečnim ali pa morda celo podporprečnin komumikacijskin spessobnostim. 1 Iz raziskave je tako izvzet del mikmo organizatij, saj predpostavljamo, da v primeru organizacij z manj kot pet zapostenimi režko najdemo nekoga, ki bi istrezal kriteriju vzorčne enote.

5 Podobno kot Mramor in Valentincic (2003, str: 748) Rot glaymi kriterij deline orgunizacij po velikesti upošlevamo stevilo zuposlenth. Pri tem se tako kot Matlay (2002, sti: 360), Barry itt Milner (2002, str; 324) opiramo na uveljavljeno merilo a doloćamje velikosti podjetij ". Evropski Uniji (Commision Recommendation of 6 May 2003, 2003/36//EC, 2. clen v dodatku), ki deli podjetja na mikmo (manj kot 10 zapostenih), majhina $(10-19$ zaposientih), sredinja (50-249) in velika (nad 250 zapostenih) podjetja. V raziskavi ta kriterij posplos̃ujemo ua vse organizacije. Pri tem je za potrebe raziskave organizacija definirama kot pravna ali fizična oseba, ki opravlja kakršnokoli dejarnost (pridobimo ali nepridobitno) na področju Republike Slovenije, izvzete so 11] zadrug̃e enote, [2] predstanništva, [3] poslowne enote. [4] podružnice $s, p+,[5]$ podrušnice, [6] orgunizucijske enote, 17] imputrane anote. [8] druge oblike detow postosnih subjekıov; [9] druge oblike postovnih subjektov, [10] druzbena podjetju, [11] krajevne skupuosii. [12] politiche strmke, [13] regissrimi lekumarjt. [14] registrirani veterinarji, $[15]$ registrirani zdravniki in zobozdruvniki, [16] zaseblui zdravstvent delaved, [17] skupnosti zavodoy, [18] ustanove in [19] rerske skupnosi ter podobne verske organizacije.

6 Izbrali sno metodo glavnih asi (ang. Principal Axis Factoring).

7 Za pridobitev optimalne rešitve (Sharma, 1996, sit: 2/1) smo uporabili kombinacijo hierarhičnih in nehierarhičnih metod razvrš̌canja y skupine. V primeru hierarhičnilt metod razvrščanja je bila uparabljena Wardova metoda, zu izračan mer podobnosti in oziroma razlic̀nosti pa je bila izbrana kvadriruna Evklidska razdalja. V primera nehterarhičnih metod smo uporubili proceduro K-MEANS oziroma metodo voditeliev. 